\author{
The Plant biodiversity of Ankara University 10. yıl (Beşevler) campus \\ İsa BAŞKÖSE ${ }^{* 1}$, Selçuk Tuğrul KÖRÜKLÜ ${ }^{1}$, Ahmet Emre YAPYAK ${ }^{1}$ \\ ORCID: 0000-0001-7347-3464; 0000-0002-7440-6818; 0000-0001-6464-2641 \\ ${ }^{1}$ Ankara Üniversitesi, Fen Fakültesi, Biyoloji Bölümü, 06100 Ankara, Turkey
}

\begin{abstract}
In this study, it was aimed to determine the seed plant diversity of Ankara University 10. Y1l (Beşevler) Campus. As a result of the study, a total of 445 taxa belonging to 281 genera from 79 different families were determined. From Gymnospermae subdivision, 31 taxa belong to 14 genera of 5 families were determined. From Angiospermae subdivision, 57 taxa from 10 families belong to Monocotyl group, 356 taxa from 63 families belong to Eudicot groups, and 1 taxa from 1 family (Nymphaceae) Non-Eudicot basal group were determined. The eight of the determined 445 taxa are endemic for Turkey with the ratio of 1,8\%. In addition, 151 of the taxa in the campus area are woody (trees or shrubs) and the remaining 294 taxa are annual or perennial herbaceous plants. In addition, 266 of the taxa in the campus area grow naturally, but the remaining 179 taxa are not natural (plantation or cultivation).
\end{abstract}

Key words: Ankara University, B4 square, campus, endemic, flora

\title{
Ankara Üniversitesi 10. yıl (Beşevler) yerleşkesinin bitki biyoçeşitliliği
}

\section{Özet}

Bu çalışmada, Ankara Üniversitesi 10. Yıl (Beşevler) yerleşkesinin tohumlu bitki çeşitliliği belirlenmesi amaçlanmıştır. Çalışma sonucunda yerleşke içerisinde 79 farklı familyadan, 281 cinse ait tür ve tür altı düzeyde toplam 445 takson tespit edilmiştir. Gymnospermae alt şubesinde 5 familyadan 14 cinse ait toplam 31 takson tespit edilmiştir. Angiospermae alt şubesi Monokotil gruba ait 10 familyadan 57 takson, Ödikotil gruba ait 63 familyadan toplam 356 takson ve Ödikotil olmayan bazal gruba ait 1 familyadan (Nymphaceae) 1 takson tespit edilmiştir. Tespit edilen 445 taksondan sadece 8 tanesi endemik olup endemizm oranı ise \% 1,8'dir. Ayrıca, yerleşke içerisinde belirlenen taksonlardan 151'i odunlu (ağaç, ağaççık veya çalı), geriye kalan 294 takson ise tek veya çok yıllık otsu bitkilerdir. İlave olarak, Kampüs alanındaki taksonların 266 tanesi doğal olarak yetişmekte fakat geriye kalan 179 takson ise plantasyon veya yetiştirme sonucu alanda bulunmaktadır.

Anahtar kelimeler: Ankara Üniversitesi, B4 karesi, endemik, flora, kampüs

\section{Giriș}

Üniversite yerleşkeleri, özellikle uygulamalı bölümler için doğal laboratuvar özelliğine sahip olup kendi içinde önemli bir biyoçeşitliliğe sahiptir [1, 2]. Köklü ve yerleşik bir yapıya sahip üniversite yerleşkeleri, biyoçeşitliliğin korunduğu alanlar olarak karşımıza çıkarken, yeni kurulan üniversitelerde inşaat, plantasyon, peyzaj ve antropojenik etiler nedeniyle biyoçeşitlilik kompozisyonu değişkenlik göstermektedir [3, 4]. Bu durumun öncelikli etkileri yerleşkelerin floristik yapısı üzerinde kendini göstermektedir. Bu sebepten dolayı ülkemizde pek çok üniversite yerleşkesinin bitki biyoçeşitliliğinin ortaya konması amacıyla floristik çalışmalar yapılmış veya yapılmaya devam edilmektedir [3, 5, 6, 7].

\footnotetext{
* Corresponding author / Haberleşmeden sorumlu yazar: Tel.: +905354130452; Fax.: +905354130452; E-mail:isabaskose@ gmail.com

(C) Copyright 2020 by Biological Diversity and Conservation $\quad$ Geliş tarihi: 24.8.2020; Yayın tarihi: 15.12.2020
} 
Ankara üniversitesi, 1946 yılında Cumhuriyetin ilanından sonra resmi olarak kurulan ilk üniversitedir. Yaklaşık 75 y1llık bir geçmişe sahip Ankara Üniversitesinin merkez kampüs olarak seçilen ve bu çalışmaya konu olan 10 . Y1l (Beşevler) Yerleşkesi, geçen 75 yıl zarfında pek çok değişime uğramış ve günümüzdeki halini almıştır. Şehir merkezi içerisinde yer almasına karşın kampüs alanının bazı bölümleri halen doğal yapısını korumaktadır. Bu yüzdendir ki kendine özgü bir biyoçeşitliliğe sahiptir. Bunun önemli göstergelerinde biri, bu çalışmanın öncesinde yapılan çalışmalarda 10 . Yı1 yerleşkesi içerisinde 162 mantar türünün belirlenmiş olmasıdır [8, 9, 10].

Buradan yola çıkarak bu çalışmayla daha önceden floristik açıdan çalışılmamış olan 10. Yıl (Beşevler) Yerleşkesinin bitki biyoçeşitliliği ortaya konmuştur.

\section{1 Çalışma alanının coğrafik durumu}

Ankara Üniversitesi 10. Yıl (Tandoğan) Yerleşkesi Ankara ili Çankaya ilçesi sınırları içerisinde ve coğrafik olarak güneyde $39.936800^{\circ} \mathrm{K}$ ve kuzeyde $39.937350^{\circ} \mathrm{K}$ paralelleri ile batıda $32.826330^{\circ} \mathrm{D}$ ve doğuda $32.835720^{\circ} \mathrm{D}$ meridyenleri arasında yer almaktadır. Kampüs çevresinde Anıtkabir, Makine Kimya Endüstrisi Kurumu, Tarihi Ankara Garı, Gazi Üniversitesi gibi çok önemli yerleşkeler bulunmaktadır. Onuncu yıl yerleşkesi yaklaşı $195.000 \mathrm{~m}^{2}$ lik bir alana sahip olup yerleşke içinde Eczacılık ve Fen Fakültelerinin yanı sıra Rektörlük, spor kompleksi ve farklı yönetim binaları bulunmaktadır. Grid kareleme sistemine göre de B4 karesi içerisinde yer almaktadır (Şekil 1).

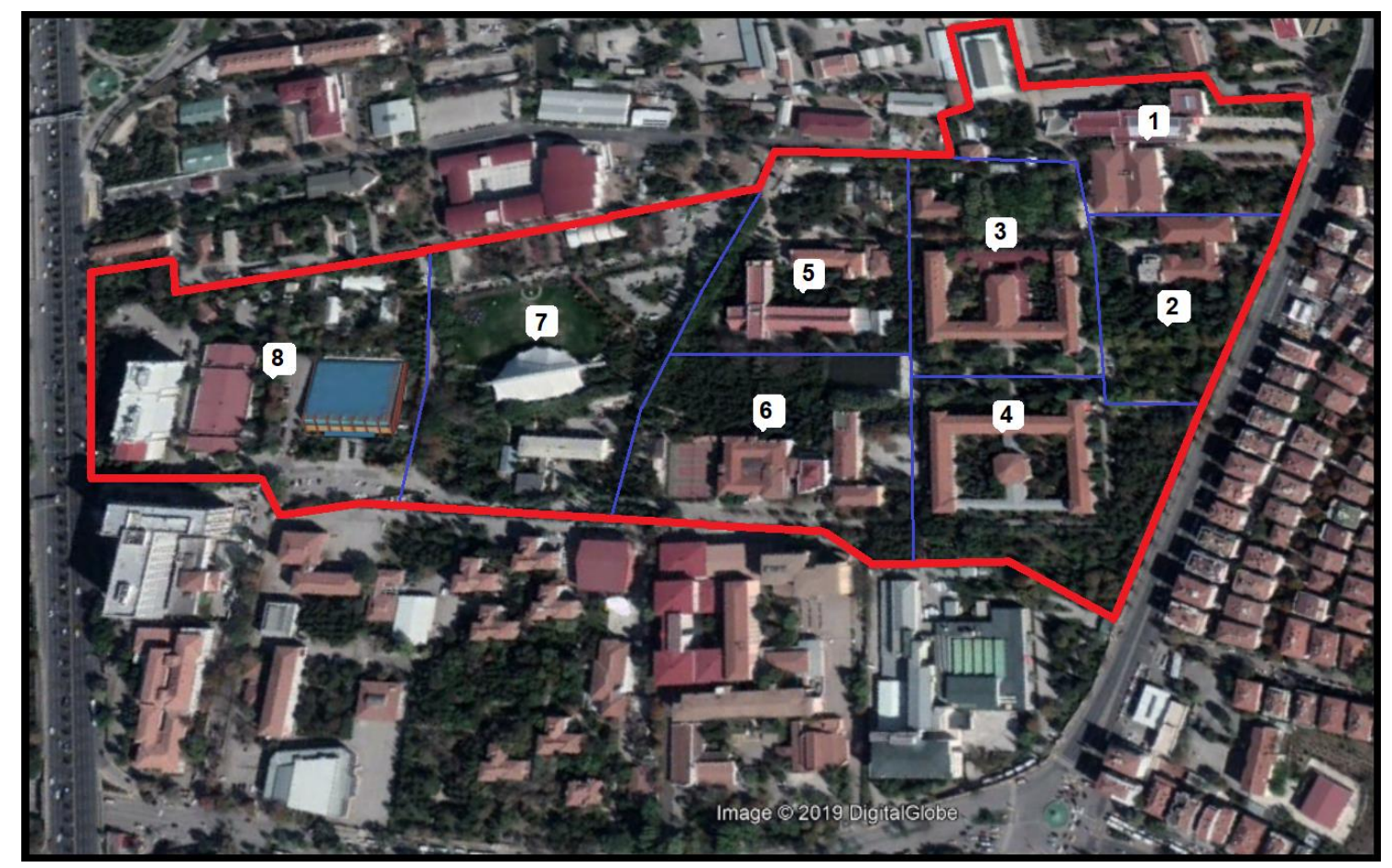

Şekil 1. Kampüs alanının uydu fotoğrafı ve parseller (— kampüs alanı sınırı, - parsel sınırları)

\section{2 Çalışma alanının iklimsel özellikleri}

Kampüs alanı, Ankara ili meteoroloji istasyonundan elde edilen verilere göre yarı kurak, alt Akdeniz iklimi katı içerisinde bulunmaktadır. Ankara'nın yıllık sıcaklık ortalaması $12.1{ }^{\circ} \mathrm{C}$, yıllık yağış ortalaması $410.5 \mathrm{~mm}^{3}$ (Şekil 2) ve ortalama nispi nem miktarı ise \% 60.7'dir. Mevsimlere göre ortalama yağış miktarları dikkate alındığında, ilkbahar aylarında toplam $140.9 \mathrm{~mm}^{3}$, yaz aylarında toplam $64.6 \mathrm{~mm}^{3}$, sonbahar aylarında toplam $84.5 \mathrm{~mm}^{3}$ ve kış aylarında toplam $120.4 \mathrm{~mm}^{3}$ yağış görülmektedir. Bu durum dikkate alındığında, Ankara ili yağış rejimi bakımından (I.K.S.Y) şeklinde ve Doğu Akdeniz yağış rejimi 2. tipi içerisinde yer almaktadır.

\section{Materyal ve yöntem}

$\mathrm{Bu}$ çalışmanın materyali, 2018 ve 2020 yılları arasında Mart-Kasım ayları arasına denk gelen vejetasyon dönemlerinde toplanan 750 bitki örneğinden oluşmaktadır. Arazi çalışmaları, alanın küçük olması sebebiyle haftada bir ve günübirlik olarak yapılmıştır.

Toplanan örnekler uygun yöntemle preslenmiş, kurutulmuş, kartonlara yapıştırılmış ve herbaryum materyali haline getirilmiştir. Örnekler Ankara Üniversitesi Fen Fakültesi Biyoloji Bölümü Herbaryumuna (Herbaryum ANK) yerleştirilmiştir. 


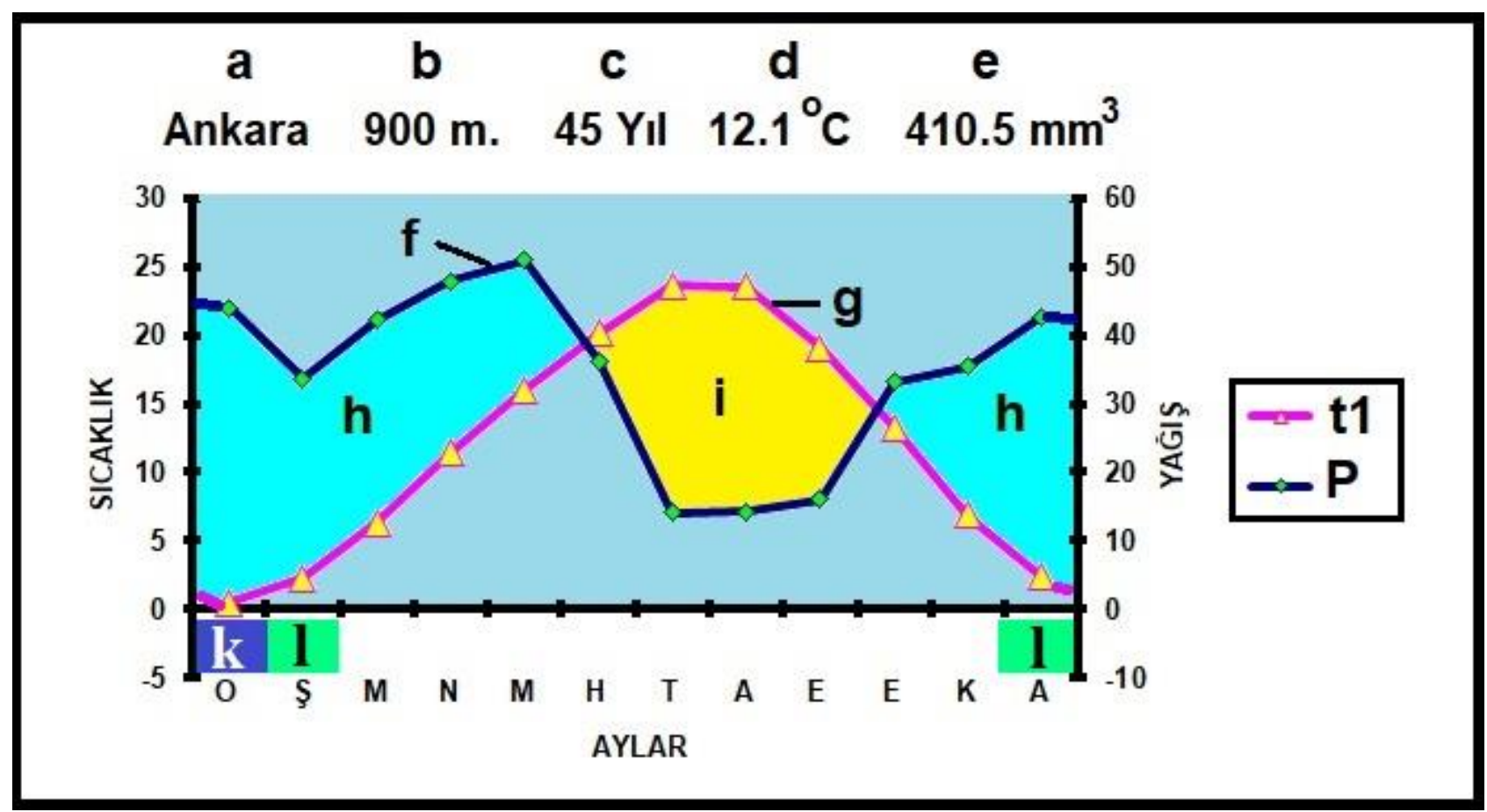

Şekil 2. Ankara ili Merkez (9. Bölge) istasyonuna ait ombrotermik iklim diyagramı; a) istasyon adı, b) istasyon rakımı, c) rasat süresi, d) yıllık ortalama sıcaklık, e) toplam yıllık yağış ortalaması, f) yağış eğrisi, g) sıcaklık eğrisi, h) yağışlı dönem, i) kurak dönem, k) muhtemel donlu aylar, l) don ihtimali olan aylar

Çalışma alanından toplanan ve doğal yayılışa sahip örnekler “Türkiye Florası” ciltleri kullanılarak [12, 13, 14], yerleşke içerisinde plantasyon veya peyzaj düzenlemeleri sonucu bulunan egzotik türler ise konuyla ilgili literatürlere $[15,16,17,18]$ göre teşhis edilmiştir. Ayrıca teşhisinde güçlük çekilen bazı taksonların teşhisi, ANK herbaryumunda bulunan örnekler ile kıyaslanmak suretiyle yapılmıştır. Belirlenen taksonların otör adlarının yazımı için "Authors of Plants Name" [19] adlı eser ile "The Plant List" ve "International Plant Names Index" gibi güncel internet siteleri temel alınmıştır [20, 21].

Çalışma sonucu belirlenen taksonlar ise APG sitemine göre düzenlenmiş ve alfabetik düzene göre listelenmiştir. Alanda plantasyon veya peyzaj düzenlenmesi sonucu yayılış gösteren taksonlar “*” işareti ile gösterilmiştir. Çalışma alanında olası endemik ve nadir bitkilerin tehlike kategorileri “Türkiye Bitkileri Kırmızı Kitabı" adlı esere göre belirlenmiş [22], ancak kategoriler IUCN version 14'e göre yeniden düzenlenmiştir [23]. Araştırma alanının küçük olmasından dolayı 8 farklı istasyona bölünmüş ve buna bağlı olarak tasonların lokalite bilgileri uzun şekilde yazılmayıp aşağıda liste halinde verilen istasyonlara ait kod numaraları kullanılmıştır (Tablo 1). Ayrıca alanda bulunan endemik ve nadir 6 adet geofit bitki taksonu için örnekleme yapılmayıp canlı örnek üzerinden teşhisleri yapılmıştır.

Çalışma alanının iklimsel özelliklerinin belirlenmesi amacıyla Tarım ve Orman Bakanlığı Devlet meteoroloji Genel Müdürlüğü Ankara ili Keçiören Meteoroloji Bölge Müdürlüğü istasyonundan elde edilen 45 yıllık sicaklık, yağ1Ş ve nem gibi veriler kullanılmıştır. Elde edilen verilerin yorumlanması için “İklim ve Biyoiklim” adlı eser temel alınmış [11] ve bu veriler doğrultusunda da Ankara ili için ombrotermik iklim diyagramı çizilmiştir (Şekil 2).

Tablo 1. Çalışma alanındaki istasyonların listesi

\begin{tabular}{|c|l|c|l|}
\hline İstasyon kodu & \multicolumn{1}{|c|}{ İstasyonlar } & İstasyon kodu & \multicolumn{1}{|c|}{ İstasyonlar } \\
\hline 1 & Eczacıllk Fakültesi çevresi & 5 & Fen Fakültesi C ve F Blok çevresi \\
\hline 2 & Rektörlük çevresi & 6 & Fen Fakültesi D Blok çevresi \\
\hline 3 & Fen Fakültesi A Blok çevresi ve iç bahçeler & 7 & Rekreasyon alanı çevresi \\
\hline 4 & Fen Fakültesi B Blok çevresi ve iç bahçeler & 8 & Olimpik yüzme havuz ve çevresi \\
\hline
\end{tabular}

Çalışma alanı haritası “Google Earth” programı kullanılarak hazırlanmıştır (Şekil 1). Alanın iklimsel verileri ise Tarım ve Orman Bakanlığı Devlet meteoroloji Genel Müdürlüğünden temin edilmiş [24] ve verilerin analizi için "İklim ve Biyoiklim" adlı eserden yararlanılmıştır [11] 


\section{Bulgular}

\section{GYMNOSPERMAE}

1. CUPRESSACEAE

*Chamaecyparis lawsoniana (A. Murr.) Parl., 5,7,8, 865 m, 22.06.2019, Başköse-4585.

*Cryptomeria japonica (Thunb. ex L.f.) D.Don, 3, 865 m, 8.07.2019, Başköse-4697.

*× Cupressocyparis leylandii (A.B.Jacks. \& Dallim.) Dallim., 3,4, 865 m, 22.06.2019, Başköse-4622.

*Cupressus arizonica Greene, 3,4, 865 m, 22.06.2019, Başköse-4599.

*Cupressus macrocarpa Harw. Ex Gordon, 7, 865 m, 22.06.2019, Başköse-4600.

*Cupressus sempervirens L., 8, 865 m, 22.06.2019, Başköse-4601.

*Juniperus chinensis L., 3,5,7, 865 m, 22.06.2019, Başköse-4612.

*Juniperus communis L. var. communis, 8, $865 \mathrm{~m}$, 22.06.2019, Başköse-4610.

*Juniperus excelsa M.Bieb., 8, 865 m, 28.06.2019, Başköse-4657.

*Juniperus horizontalis Moench, 5, 865 m, 22.06.2019, Başköse-4613.

*Juniperus sabina L., 2,4, 865 m, 22.06.2019, Başköse4594.

*Juniperus virginiana L. 3,4, 865 m, 22.06.2019, Başköse-4598

*Platycladus orientalis (L.) Franco., $1 \rightarrow 6,865 \mathrm{~m}$, 7.06.2019, Başköse-4534.

*Thuja occidentalis L., 2,4, 22.06.2019, Başköse-4602.

\section{PINACEAE}

*Abies cilicica (Antoine \& Kotschy) Carrière subsp. cilicica, 3,4, 865 m, 22.06.2019, Başköse-4574.

*Abies nordmanniana (Stev.) Spach. subsp. nordmanniana, 8, 365 m, 24.07.2020, Başköse-4938.

*Abies pinsapo Boiss., 5, 865 m, 22.06.2019, Başköse4588.

*Cedrus atlantica (Endl.) Manetti ex Carr, 2, 865 m, 22.06.2019, Başköse-4589.

*Cedrus deodora (Roxb. ex Lamb.) G.Don, 2,4, 865 m, 22.06.2019, Başköse-4591.

*Cedrus libani A.Rich. var. libani, $1 \rightarrow 7,865 \mathrm{~m}$, 22.06.2019, Başköse-4597.

*Picea abies (L.) H.Karst., 7, 865 m, 30.03.2020, Başköse-4898.

*Picea orientalis (L.) Link., 2,4, 865 m, 22.06.2019, Başköse-4577.

*Picea pungens Engelm., 2 $\rightarrow 6,865$ m, 22.06.2019, Başköse-4623.

*Pinus brutia L. var. brutia, 2, 865 m, 22.06.2019, Başköse-4590.

*Pinus nigra Arnold. subsp. pallasiana (Lamb.) Holmboe var. pallasiana, $3 \rightarrow 8,865 \mathrm{~m}, 16.04 .2019$, Başköse-4186 ve 4595.

*Pinus nigra Arnold. subsp. pallasiana (Lamb.) Holmboe var. fastigiata, 2, 865 m, 28.06.2019, Başköse4663. Endemik.

*Pinus pinea L. 5, 865 m, 22.06.2019, Başköse-4587
*Pinus sylvestris L. var. hamata, 3,7, $865 \mathrm{~m}$, 16.04.2018, Başköse-4185.

*Pinus wallichiana A.B.Jacks., 3,4, 865 m, 16.05.2018, Başköse-4234.

\section{EPHEDRACEAE}

*Ephedra major Host., 1, 865 m, 19.06.2019, Başköse4555.

\section{GINKGOACEAE}

*Ginkgo biloba L., 1,4,5, 865 m, 28.06.2019, Başköse4675.

\section{TAXACEAE}

*Taxus baccata L., 1,2, 865 m, 19.06.2019, Başköse4553.

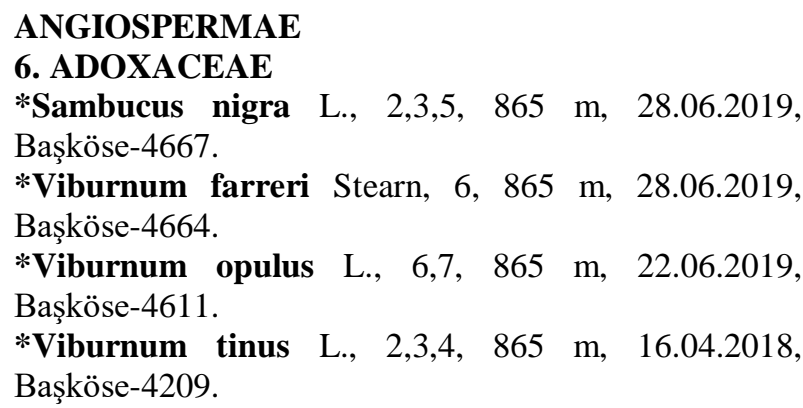

\section{AMARANTHACEAE}

Amaranthus albus L., 6, 865 m, 17.07.2018, Başköse4382 ve 4383.

Amaranthus blitoides S.Watson, 7, 865 m, 29.06.2018, Başköse-4354

Amaranthus retroflexus L., 5,6, 865 m, 29.06.2018, Başköse-4346 ve 4392.

Amaranthus viridis L., 5, 17.09.2018, Başköse-4420.

Atriplex micrantha Ledeb., 6, $865 \mathrm{~m}, 22.06 .2019$, Başköse-4617.

Atriplex laevis Ledeb., 6, 865 m, 29.06.2018, Başköse4347.

Atriplex patula L., 5,6, 865 m, 22.06.2019, Başköse4615.

Atriplex prostrata Boucher ex DC., 5, $865 \mathrm{~m}$, 17.09.2018, Başköse-4423.

Atriplex rosea L., 7, 865 m, 22.06.2019, Başköse-4616. Atriplex sagittata Borkh., 4,5, 865 m, 28.06.2019, Başköse-4645.

Beta lomatogona Fisch. \& C.A.Mey., 5, 865 m, 21.05.2020, Başköse-4924.

Chenopodium album L. subsp. album var. album, 5,6,7, 865 m, 17.09.2018, Başköse-4352, 4397, 4424 ve 4425.

Chenopodium opulifolium Schrad. ex W.D.J.Koch \& Ziz, 5,6, 865 m, 4.09.2018, Başköse-4413 ve 4419

Chenopodium urbicum L., 5,7, 865 m, 13.08.2018, Başköse-4391 ve 4421.

Chenopodium vulvaria L., 5,6,7, 865 m, 29.06.2018, Başköse-4352 ve 4422. 


\section{AMARYLLIDACEAE}

*Allium karamanoglui Koyuncu \& Kollmann, 3, 29.04.2020, Başköse-4904, Endemik.

*Allium neopolitanum Cirillo, 1, 865 m, 29.04.2020, Başköse-4906.

*Allium orientale Boiss., 1, 865 m, 7.06.2019, Başköse4525.

*Allium paniculatum L. subsp. paniculatum, 3, 865 m, 8.07.2019, Başköse-4737.

Allium scorodoprasum L. subsp. rotundum L., 7, 865 m, 29.06.2020, Başköse-4935.

*Allium sativum L., 5, 865 m, 19.06.2019, Başköse4567.

*Galanthus elwesii Hook.f. var. elwesii, 3, 865 m, 13.03.2020, Başköse-4889.

*Narcissus pseudonarcissus L., 3, 865 m, 19.03.2019, Başköse-4887.

*Sternbergia candida B.Mathew \& T.Baytop, 3, 865 m, 14.02.2019, Endemik.

*Sternbergia vernalis (Mill.) Gorer \& J.H.Harvey, 3, $865 \mathrm{~m}, 8.10 .2018$.

\section{ANACARDIACEAE}

*Cotinus coggygria Scop., 4,6,7,8, 865 m, 16.05.2018, Başköse-4260.

*Rhus typhina L. 3,7, 865 m, 16.05.2018, Başköse4295.

\section{APIACEAE}

Anthriscus caucalis M.Bieb., 3, 865 m, 23.05.2018, Başköse-4316.

Anthriscus nemorosa (M.Bieb.) Spreng., 3,4, 865 m, 23.05.2018, Başköse-4322.

Echinophora tenuifolia L. subsp. sibthorpiana (Guss.) Tutin, 4, 865 m, 22.07.2019, Başköse-4749.

Daucus carota L., 4, 865 m, 02.07.2018, Başköse-4373. Eryngium campestre L., 4, 865 m, 13.06.2019, Başköse-4548.

Lisaea papyracea Boiss., 5, 865 m, 865 m, 07.06.2019, Başköse-4523.

Malabaila secacul (Mill.) Boiss. subsp. secacul, 4,6, 865 m, 23.05.2018, Başköse-4304.

Pimpinella peregrina L., 3, $865 \mathrm{~m}$, 23.05.2018, Başköse-4324.

Torilis arvensis (Huds.) Link subsp. arvensis, 3,4,6, 865 m, 01.06.2018, Başköse-4334.

Torilis nodosa (L.) Gaertn., 4,6, 865 m, 29.05.2019, Başköse-4505

\section{APOCYNACEAE}

*Cynanchum acutum L. subsp. acutum, 7, $865 \mathrm{~m}$, 28.06.2019, Başköse-4688.

*Vinca major L. subsp. major, 2,3,5, 865 m, 8.07.2019, Başköse-4694.

*Vinca minor L., 2,3,4, 865 m, 28.06.2019, Başköse4672.

\section{AQUIFOLIACEAE}

*Ilex aquifolium L., 3, 865 m, 28.06.2019, Başköse4659.

\section{ARACEAE}

Arum rupicola Boiss. var. rupicola, 3, $865 \mathrm{~m}$, 29.04.2020, Başköse-4903.

\section{ARALIACEAE}

*Hedera colchica (K.Koch) K.Koch, 6, 865 m, 28.06.2019, Başköse-4643.

Hedera helix L., 1,3,6,8, 865 m, 8.07.2019, Başköse4712.

\section{ASPARAGACEAE}

*Asparagus officinalis L. subsp. officinalis, 5, $865 \mathrm{~m}$, 13.06.2019, Başköse-4543.

*Hyacinthus oriantalis L. subsp. orientalis, 3,5, 865 m, 10.02.2019, Başköse-4894.

*Muscari neglectum Guss. ex Ten., 3,6, 865 m, 17.04.2019, Başköse-4888.

*Ornithogalum lanceolatum Labill., 3, $865 \mathrm{~m}$, 10.02.2019, Başköse-4890.

*Ornithogalum sphaerocarpum A.Kern., 4, 865 m, 23.05.2018, Başköse-4311.

*Ornithogalum umbellatum L., 3,4,5, $865 \mathrm{~m}$, 16.04.2018, Başköse-4201.

* Ruscus aculeatus L. var. aculeatus, 3, $865 \mathrm{~m}$, 28.06.2019, Başköse-4634.

*Scilla bifolia L., 3, 865 m, 6.02.2019, Başköse-4895.

*Scilla luciliae (Boiss.) Speta, 3, 865 m, 6.02.2019, Endemik.

*Yucca filamentosa L., 2,3,5,8, 865 m, 22.06.2019, Başköse-4621.

\section{ASPHODELACEAE}

*Hemerocallis fulva (L.) L. var. fulva, 2,3, $865 \mathrm{~m}$, 22.06.2019, Başköse-4583.

\section{ASTERACEAE}

Achillea arabica Kotschy, 2,5, 865 m, 16.05.2018, Başköse- 4240.

Achillea millefolium L. subsp. millefolium var. millefolium, 2, 865 m, 23.05.2018, Başköse- 4299, 4372 ve 4385 .

Arctium minus (Hill) Bernh., 3,5,8, 1.06.2018, 865 m, Başköse-4330

Artemisia vulgaris L., 5, 865 m, 25.09.2018, Başköse4436.

Bellis perennis L., 3,4, 865 m, 19.06.2019, Başköse4558.

Carduus nutans L. (s.1.), 4, 865 m, 23.05.2018, Başköse- 4315.

Carduus pycnocephalus L. var. pycnocephalus, 1,3,4, 865 m, 16.04.2018, Başköse-4206.

Centaurea solstitialis L. subsp. solstitialis, 8, 8.07.2019, Başköse-4704.

Chardinia orientalis (L.) Kuntze, 4, 865 m, 23.05.2018, Başköse-4314.

Chondrilla juncea L., 1,2,3,6,7, 865 m, 28.08.2018, Başköse- 4409.

Cichorium intybus L., 1,2,3,5,6, 865 m, 1.06.2018, Başköse-4328 ve 4551. 
Cirsium arvense (L.) Scop. subsp. vestitum, 1,2,4, 23.05.2018, 865 m, Başköse-4320.

Cirsium vulgare (Savi) Ten., 4,6, 865 m, 1.06.2018, Başköse- 4331.

Conyza bonariensis (L.) Cronquist, 7, $865 \mathrm{~m}$, 25.09.2018, Başköse-4440.

Conyza canadensis (L.) Cronquist, 2,3,7, $865 \mathrm{~m}$, 6.07.2018, Başköse-4381 ve 4396.

Crepis alpina L., 1,3,4, 865 m, 16.05.2018, Başköse4218

Crepis foetida L. subsp. rhoeadifolia (M.Bieb.) Čelak., 2,3,4, 865 m, 16.05.2018, Başköse- 4229.

Crepis pulchra L. subsp. pulchra, 3, 865 m, 16.04.2018, Başköse-4217 ve 4225.

Crepis sancta (L.) Bornm., 1,3,6, 865 m, 16.04.2018, Başköse-4219

Crupina crupinastrum (Moris) Vis., 1,4, $865 \mathrm{~m}$, 16.05.2018, Başköse- 4228.

Cyanus depressus (M.Bieb.) Soják, 5, 865 m, 2.05.2018, Başköse-4767.

Filago pyramidata L., 4, 865 m, 13.06.2019, Başköse4539.

Lactuca serriola L., $1 \rightarrow 6,865$ m, 28.06.2019, Başköse4648 ve 4708.

Lactuca tuberosa Jacq., 3, 865 m, 19.06.20109, Başköse-4569.

Lactuca viminea (L.) J.Presl \& C.Presl, 4, 865 m, 22.07.2019, Başköse-4748.

Lapsana communis L. subsp. intermedia (M.Bieb.) Hayek var. intermedia, 5, 865 m, 29.06.2020, Başköse4936.

Onopordum anatolicum (Boiss.) Boiss. \& Heldr. ex Eig, 3,4, 865 m, 2.07.2018, Başköse-4374,

Picnomun acarna (L.) Cass., 3, 865 m, 8.07.2019, Başköse-4692.

Pilosella pilisquama (Nägeli \& Peter) Dostál, 4, 865 m, 28.06.2019, Başköse-4642.

Pilosella piloselloides (Vill.) Soják subsp. magyarica (Peter) S.Bräut. \& Greuter, 4, 865 m, 8.07.2019, Başköse-4699.

Santolina chamaecyparissus L., 6, 865 m, 28.06.2019, Başköse-4650.

Scorzonera cana (C.A.Mey.) Griseb. var. jacquiniana, 1, 865 m, 16.04.2018, Başköse-4221 ve 4227.

Senecio leucanthemifolius Poir. subsp. vernalis (Waldst. \& Kit.) Greuter, $1 \rightarrow 6,865$ m, 16.04.2018, Başköse-4758.

Senecio vulgaris L., 3,4,6, 865 m, 30.03.2020, Başköse4896.

Sonchus asper (L.) Hill subsp. glaucescens (Jord.) Ball ex Ball, 2,3,4,5, 865 m, 28.06.2019, Başköse-4635.

Sonchus oleraceus (L.) L., 5, 865 m, 16.04.2018, Başköse-4218.

Tanacetum parthenium (L.) Sch.Bip., 5, $865 \mathrm{~m}$, 9.06.2019, Başköse-4565.

Taraxacum officinale (L.) Weber ex F.H.Wigg, $1 \rightarrow 8$, 865 m, 28.06.2019, Başköse-4687.

Taraxacum serotinum (Waldst. \& Kit.) Fisch., 5, 865 m, 28.08.2018, Başköse-4411.
Tragopogon latifolius Boiss. var. angustifolius Boiss., 3,4,5, 865 m, 16.06.2018, Başköse-4239.

Tragopogon porrifolius L. subsp. longirostris (Sch.Bip.) Greuter, 3,4,5, 865 m, 16.05.2018, Başköse4257.

Tripleurospermum tenuifolium (Kit.) Freyn ex Freyn, 2,3, 865 m, 7.06.2019, Başköse-4491 ve 4530.

Xanthium spinosum L., 3,4, 865 m, 26.07.2018, Başköse-4388.

\section{BERBERIDACEAE}

*Berberis crataegina DC., 4, 865 m, 16.04.2018, Başköse-4214 ve 4384.

*Berberis $\times$ media Groot. ex Boom, 2, $865 \mathrm{~m}$, 8.07.2019, Başköse-4693.

*Berberis thunbergii DC., 1,5, 865 m, 22.06.2019, Başköse-4614.

*Berberis veitchii C.K.Schneid., 1, 865 m, 7.06.2019, Başköse-4528.

*Berberis vulgaris L., 4,5, 6.07.2018, 865 m, Başköse4378.

*Mahonia aquifolium (Pursh) Nutt., $1 \rightarrow 8,865 \mathrm{~m}$, 22.06.2019, Başköse-4609.

\section{BETULACEAE}

*Betula pendula Roth., 1,3,7, 865 m, 22.06.2019, Başköse-4606.

*Carpinus betulus L., 7, 865 m, 28.06.2019, Başköse4687.

*Corylus avellana L. var. avellana, 3,5, $865 \mathrm{~m}$, 22.06.2019, Başköse-4624.

\section{BIGNONIACEAE}

*Campsis radicans (L.) Seem., 8, 865 m, 8.07.2019 Başköse-4707.

*Catalpha bignonioides Walter., 6,7, 865 m, 2.06.2019, Başköse-4575.

\section{BORAGINACEAE}

Anchusa azurea Mill., 5,6, 865 m, 20.05.2019, Başköse4492.

Anchusa leptophylla Roem. \& Schult. subsp. leptophylla, 5,8, 865 m, 16.05.2018, Başköse- 4289 .

Asperugo procumbens L., 2,3,5, 865 m, 13.03.2020, Başköse-4892.

Cynoglossum creticum Miller, 4, 865 m, 29.05.2019, Başköse-4514.

Buglossoides arvensis (L.) I.M.Johnst. subsp. sibthorpiana (Griseb.) R.Fern., 5, 865 m, 16.04.2018, Başköse-4211.

Echium italicum L., 7, 865 m, 1.06.2018, Başköse4333.

Echium vulgare L. subsp. vulgare, 5, $865 \mathrm{~m}$, 29.06.2020, Başköse-4935.

Heliotropium lasiocarpum Fisch. \& C.A.Mey., 5, 865 m, 28.08.2018, Başköse-4406 ve 4561 .

Rochelia disperma (L.f.) K.Koch var. disperma, 5, 865 m, 16.04.2018, Başköse-4187. 


\section{BRASSICAEAE}

Alyssum desertorum Stapf, 4, 865 m, 29.03.2019, Başköse-4481.

Alyssum huetii Boiss., 5, 865 m, 16.05.2018, Başköse4252.

Brassica nigra (L.) K.Koch, 5,6, 865 m, 16.04.2019, Başköse-4768.

Calepina irregularis (Asso) Thell., 3, $865 \mathrm{~m}$, 29.03.2019, Başköse-4480 ve 4484.

Capsella bursa-pastoris (L.) Medik., $2 \rightarrow 7,865 \mathrm{~m}$, 19.06.2019, Başköse-4560.

Cardamine hirsuta L., 3, 865 m, 4.03.2019, Başköse4471 ve 4479.

Clypeola jonthlaspi L., 4, 865 m, 12.04.2019, Başköse4482.

Conringia planisiliqua Fisch. \& C.A.Mey., 4, 865 m, 2.07.2018, Başköse-4370 ve 4490.

Descurainia sophia (L.) Webb ex Prantl, 3,5, 865 m, 13.04.2020, Başköse-4899.

Diplotaxis tenuifolia (L.) DC., 3,8, 865 m, 16.05.2018, Başköse-4286.

Draba verna L., 4,6, 865 m, 8.03.2019, Başköse-4472.

Eruca vesicaria (L.) Cav., 4, 865 m, 16.04.2018, Başköse-4210.

Lepidium chalepense L., $1 \rightarrow 3,5,865$ m, 16.05.2018, Başköse-4285.

Lepidium latifolium L., 3,4, 865 m, 23.05.2018, Başköse-4301.

Lepidium perfoliatum L., 1, 865 m, 17.04.2019, Başköse-4488.

Noccaea perfoliata (L.) Al-Shehbaz, 3,4, $865 \mathrm{~m}$, 8.03.2019, Başköse-4473.

Rapistrum rugosum (L.) All., 1, 865 m, 23.05.2018, Başköse-4323.

Sinapis arvensis L., 6,7, 865 m, 16.04.2018, Başköse4181.

Sisymbrium altissimum L., 4, 865 m, 16.04.2018, Başköse-4200.

Sisymbrium loeselii L., $3 \rightarrow 7,865$ m, 16.04.2018, Başköse-4216 ve 4249.

\section{BUXACEAE}

*Buxus balearica Lam., 5,6, 22.03.2019, 865 m, Başköse-4237, 4516 ve 4477

*Buxus microphylla Siebold \& Zucc., 2, $865 \mathrm{~m}$, 10.06.2020, Başköse-4931.

*Buxus sempervirens L. subsp. sempervirens, 5, 865 m, 22.03.2019, Başköse-4476.

\section{CAMPANULACEAE}

Campanula lyrata Lam. subsp. lyrata, 3, $865 \mathrm{~m}$, 20.05.2019, Başköse-4498.

Campanula rapunculoides L., 5, 865 m, 2.07.2018, Başköse-4364 ve 4573.

\section{CANNABACEAE}

*Celtis australis L. subsp australis, 1,4, $865 \mathrm{~m}$, 19.06.2019, Başköse-4554.

\section{CANNACEAE}

*Canna indica L., 4, 865 m, 22.07.2019, Başköse-4750.

\section{CAPRIFOLIACEAE}

*Lonicera x bella Zabel, 5, 865 m, 22.06.2019, Başköse4618.

*Lonicera caprifolium L., 6, 865 m, 7.06.2019, Başköse-4520.

*Lonicera fragrantissima Lindl. \& J. Paxton, 8, 865 m, 22.06.2019, Başköse-4605.

*Lonicera tatarica L., 2,3, 865 m, 28.06.2019, Başköse4665.

*Pterocephalus plumosus (L.) Coult., 4, $865 \mathrm{~m}$, 1.06.2018, Başköse-4336, 4375 ve 4538.

Scabiosa rotata M.Bieb., 4, 865 m, Başköse-4337.

Symphoricarpus albus (L.) S.F.Blake, 2,4,5, $865 \mathrm{~m}$, Başköse-4570.

Valerianella coronata (L.) DC., 4, 865 m, Başköse4268.

Valerianella vesicaria (L.) Moench, 4, 865 m, Başköse4269.

\section{CARYOPHYLLACEAE}

Arenaria sepyllifolia L. subsp. sepyllifolia, 6, $865 \mathrm{~m}$, 29.05.2019, Başköse-4504.

Bufonia virgata Boiss., 4, 865 m, 28.08.2018, Başköse4405.

Cerastium dichotomum L., 4, 865 m, 12.05.2020, Başköse-4922.

*Cerastium tomentosum L., 1,3, 865 m, 29.04.2020, Başköse-4905.

Gypsophila viscosa Murray, 4, 865 m, 16.05.2018, Başköse-4273.

Holosteum umbellatum L. var. umbellatum, 4, 865 m, 8.03.2019, Başköse-4474.

Minuartia hamata (Hausskn.) Mattf., 6, $865 \mathrm{~m}$, 16.05.2018, Başköse-4270.

Silene dichotoma Ehrh. subsp. dichotma, 6, $865 \mathrm{~m}$, 25.05.2019, Başköse-4503.

Silene vulgaris (Moench) Garcke subsp. vulgaris, 3, 865 m, 25.05.2019, Başköse-4502.

Stellaria media (L.) Vill., $2 \rightarrow 5,865$ m, 28.06.2019, Başköse-4637.

Velezia rigida L., 6, 865 m, 28.06.2019, Başköse-4678.

\section{CELASTRACEAE}

*Euonymus japonicus Thunb., 2,3,4,7, $865 \mathrm{~m}$, 28.06.2019, Başköse-4670.

30. COLCHICACEAE

*Colchicum balansae Planch., 3, 865 m, 25.09.2018.

\section{CONVOLVULACEAE}

Convolvulus arvensis L., $1 \rightarrow 8,865 \mathrm{~m}, 16.05 .2018$, Başköse-4255 ve 4552.

Convolvulus galaticus Rost. ex Choisy, 5,7, $865 \mathrm{~m}$, 16.05.2018, Başköse-4282.

\section{CORNACEAE}

*Cornus alba L., 7, 865 m, 28.06.2019, Başköse-4690. 


\section{CUCURBITACEAE}

Bryonia multiflora Boiss. \& Heldr., 3,4,5, 865 m, 16.04.2018, Başköse-4188 ve 4371.

\section{ELAEAGNACEAE}

*Elaeagnus angustifolia Wahl. var. angustifolia, 2,5, 865 m, 20.05.2019, Başköse- Başköse-4494.

*Elaeagnus rhamnoides (L.) A.Nelson, 2, 865 m, 1.06.2018, Başköse-4339.

\section{EUPHORBIACEAE}

Chrozophora tinctoria (L.) A.Juss., 5, $865 \mathrm{~m}$, 28.08.2018, Başköse-4400.

Euphorbia chamaesyce L., 3,4,5, 865 m, 28.08.2018, Başköse-4407 ve 4418.

Euphorbia peplus L. var. peplus, $3,4,865 \mathrm{~m}$, 16.04.2018, Başköse-4197.

\section{FABACEAE}

*Albizzia julibrissin Durazz., 3,5, 865 m, 22.06.2019, Başköse-4628.

*Amorpha fruticosa L., 4, 865 m, 25.05.2019, Başköse4515.

Astragalus beypazaricus Podlech \& Aytaç, 5, $865 \mathrm{~m}$, 22.06.2019, Başköse-4620. Endemik.

Astragalus hamosus L., 4, 865 m, 16.04.2018, Başköse4190 ve 4194.

Astragalus xylobasis Freyn \& Bornm., 6, $865 \mathrm{~m}$, 10.06.2020, Başköse-4929.

*Cercis siliquastrum L. subsp. siliquastrum, 2,3,4,7,8, 865 m, 28.06.2019, Başköse-4641.

Coronilla scorpioides (L.) W. D. J. Koch, 4, 865 m, 20.05.209, Başköse-4496.

*Gleditsia triacanthos L., 1,2,3,8, 865 m, 8.07.2019, Başköse-4696.

*Laburnum anagyroides Medik, 1, 865 m, 16.05.2018, Başköse-4231.

Lotus corniculatus L. var. tenuifolius L., 2,3,4,7, 865 m, 16.05.2018, Başköse-4262.

Medicago brachycarpa M.Bieb., 4, 865 m, 16.05.2018, Başköse-4267 ve 4310.

Medicago lupulina L., 4,7,8, 865 m, 16.04.2018, Başköse-4181 ve 4203.

Medicago minima (L.) L. var. minima, 2,4, $865 \mathrm{~m}$, 2.05.2019, Başköse-4196.

Medicago monantha (C.A.Mey.) Trautv., 3,4, 865 m, 16.04.2018, Başköse-4195.

Medicago monspeliaca (L.) Trautv., 4, $865 \mathrm{~m}$, 16.05.2018, Başköse-4266.

Medicago orbicularis (L.) Bartal., 4, 865 m, 16.05.2018, Başköse-4242.

Medicago phrygia (Boiss. \& Balansa) E.Small, 3,4, 865 m, 16.05.2018, Başköse-4244.

Medicago polymorpha L. subsp. polymorpha, 3,4,7,8, 865 m, 16.05.2018, Başköse-4253 ve 4305.

Medicago rigidula (L.) All. var. rigidula, 4,7, $865 \mathrm{~m}$, 23.05.2018, Başköse-4309.

Medicago sativa L. subsp. sativa, $1,3,5,865 \mathrm{~m}$, 16.05.2018, Başköse-4292,
Melilotus officinalis (L.) Pall., 3,4,5,6, $865 \mathrm{~m}$, 16.05.2018, Başköse-4248 ve 4340.

Onobrychis oxydonta Boiss. var. armena (Boiss. \& Huet.) Aktoklu, 4, 865 m, 23.05.2018, Başköse-4313.

Pisum sativum L., 4, 865 m, 25.05.2019, Başköse-4509.

*Robinia pseudoacacia L., 2,3,4,8, 865 m, 8.07.2019, Başköse-4698.

Securigera varia (L.) Lassen., 4, 865 m, 23.05.2018, Başköse-4307.

Sophora pendula Spach, 4, 865 m, 8.07.2019, Başköse4700.

Styphnolobium japonicum (L.) Schott, 2,3,4,5,7, 865 m, 8.07.2019, Başköse-4706.

Trifolium arvense L. var. arvense, 4, $865 \mathrm{~m}, 1.06 .2018$, Başköse-4335.

Trifolium campestre Schreb. subsp. campestre var. campestre, 4,5,6, 865 m, 16.05.2018, Başköse-4243.

Trifolium pratense $\mathrm{L}$. var. pratense, $3,4,5,7,865 \mathrm{~m}$, 16.04.2018, Başköse-4205.

Trifolium repens $\mathrm{L}$. var. repens, 2,4,7,8, $865 \mathrm{~m}$, 16.05.2018, Başköse-4232.

Trifolium resupinatum $\mathrm{L}$. var. resupinatum, $7,865 \mathrm{~m}$, 16.05.2018, Başköse-4283.

Trigonella capitata Boiss., 7, $865 \mathrm{~m}, 16.05 .2018$, Başköse-4281.

Trigonella spruneriana Boiss., 4, 865 m, 23.05.2018, Başköse-4308.

Vicia narbonensis L. var. narbonensis, 4, $865 \mathrm{~m}$, 10.05.2019, Başköse-4487.

Vicia sativa subsp. nigra (L.) Ehrh. var. segetalis (Thuill.) Ser. ex DC., 7, 865 m, 16.04.2018, Başköse4183 ve 4286.

*Wisteria sinensis (Sims) Sweet, 4, 865 m, 7.06.2019, Başköse-4524.

\section{FAGACEAE}

*Castanea sativa Mill., 3, 865 m, 13.06.2019, Başköse4544.

*Quercus robur L. subsp. robur, $1 \rightarrow 6,865 \mathrm{~m}$, 8.07.2019, Başköse-4695.

\section{GERANIACEAE}

Erodium cicutarium (L.) L'Hér. subsp. cicutarium, $3 \rightarrow 8,865$ m, 28.06.2019, Başköse-4644.

Geranium robertianum L., 5,6, 865 m, 16.05.2018, Başköse-4208.

Geranium rotundifolium L., 3,4,5, 865 m, 16.05.2018, Başköse-4296.

Geranium tuberosum L., 4, 865 m, 7.04.2019, Başköse$4727 \mathrm{a}$.

\section{GROSSULARIACEAE}

* Ribes aureum Pursh, 8, 865 m, 22.06.2019, Başköse4608.

\section{HYDRANGEACEAE}

*Philadelphus coronarius L., 4,5, 865 m, 7.06.2019, Başköse-4531. 


\section{HYPERICACEAE}

Hypericum perforatum L., 7, 865 m, 12.06.2019.

\section{IRIDACEAE}

*Crocus sativus L., 5, 865 m, 14.11.2018.

Crocus ancyrensis (Herb.) Mav., 3,5, 865 m, 6.03.2020, Başköse-4886.

*Iris x germanica L., 1,8, 865 m, 22.06.2019, Başköse4607.

\section{JUGLANDACEAE}

*Juglans regia L., 4,7, 865 m, 22.06.2019, Başköse4603.

\section{LAMIACEAE}

Ajuga chamaepitys (L.) Schreb. subsp. chia (Schreb.) Arcang., 4,5, 865 m, 16.05.2018, Başköse-4271.

Ajuga reptans L., 3, 865 m, 17.04.2019, Başköse-4483. Ballota nigra L. subsp. anatolica P.H. Davis, 1, $865 \mathrm{~m}$, 29.06.2018, Başköse-4344.

Lamium amplexicaule L. var. amplexicaule, 1,3,4, 865 m, 12.03.2019, Başköse-4757.

Lamium orientale (Fisch. \& C.A.Mey.) E.H.L.Krause., 5, 865 m, 15.05.2018, Başköse-4769.

Lamium purpureum $\mathrm{L}$. var. purpureum, 3,4,5, $865 \mathrm{~m}$, 26.02.2019.

Lavandula angustifolia Mill. subsp. angustifolia, 7, 865 m, 28.06.2019, Başköse-4649.

Marrubium vulgare L., 5, 865 m, 25.05.2019. Başköse4500.

Melissa officinalis L. subsp. officinalis, $5,865 \mathrm{~m}$, 28.06.2019, Başköse-4657.

Prunella vulgaris L., 4, 865 m, 2.07.2018, Başköse4366.

*Rosmarius officinalis L., 6, 865 m, 16.04.2018, Başköse-4182.

Salvia aytacii Vural \& Adigüzel, 5, 865 m, 22.06.2019, Başköse-4619. Endemik.

Sideritis montana L. subsp. remota (d'Urv.) P.W.Ball, 4, 865 m, 13.06.2019, Başköse-4537.

Ziziphora tenuior L., 5, 865 m, 21.05.2020, Başköse4923.

\section{LILIACEAE}

Gagea villosa (M.Bieb.) Sweet var. villosa, 1, $865 \mathrm{~m}$, 13.03.2020, Başköse-4893.

*Tulipa armena Boiss. var. armena, 1,3,4,5, $865 \mathrm{~m}$, 30.03.2020, Başköse-4897.

\section{MALVACEAE}

Alcea rosea L., 4,5,7, 865 m, 28.06.2019, Başköse-4654. *Hibiscus syriacus L., 2, 865 m, 22.06.2019, Başköse4592.

Malva neglecta Wallr., 3,4,5, $865 \mathrm{~m}, 16.05 .2018$, Başköse-4222 ve 4259 .

Malva sylvestris L., 3, 865 m, 19.06.2019, Başköse4559.

Malvella sherardiana L., 4, $865 \mathrm{~m}, \quad$ 13.06.2019, Başköse-4550.
*Tilia cordata Mill., 5, 865 m, 22.06.2019, Başköse4626.

*Tilia platyphyllos Scop. var. platyphyllos, 4, $865 \mathrm{~m}$, 16.05.2018, Başköse-4293.

*Tilia tomentosa Moench., 1,2,3,7,8, 865 m, 2.07.2018, Başköse-4368.

\section{MORACEAE}

*Ficus carica L. subsp. carica, 1,6, 865 m, 28.06.2019, Başköse-4653.

*Maclura pomifera (Raf.) C.K.Schneid., $1 \rightarrow 5,865$ m, 8.07.2019, Başköse-4710.

*Morus alba L., 3,4,5, 865 m, 28.06.2019, Başköse4651.

*Morus nigra L., 2,3,4, 865 m, 28.06.2019, Başköse4581.

\section{NYMPHACEAE}

*Nymphaea alba L., 3,4,8, 865 m, 28.06.2019, Başköse4586.

\section{OLEACEAE}

*Forsythia $\mathbf{x}$ intermedia Zebel, $1 \rightarrow 8,865 \mathrm{~m}$, 28.06.2019, Başköse-4640.

*Fraxinus americana L., 1, 865 m, 13.06.2019, Başköse-4527.

*Fraxinus angustifolia Vahl. subsp. angustifolia, 2,5,6,7, 865 m, 23.05.2018, Başköse-4318.

*Fraxinus excelsior L. subsp. excelsior, 7,8, $865 \mathrm{~m}$, 28.06.2019, Başköse-4674.

*Jasminum floridum Bunge, 5, 865 m, 6.05.2018, Başköse-4251.

*Jasminum fruticans L., 1,3,4, $865 \mathrm{~m}, 28.06 .2019$, Başköse-4633.

*Ligustrum japonicum Thunb., 1,5, 865 m, 28.06.2019, Başköse-4660.

*Ligustrum vulgare L., $1 \rightarrow 8,865 \mathrm{~m}, 16.05 .2018$, Başköse-4233.

*Syringa vulgaris $\mathrm{L}$., $1 \rightarrow 5,8,865 \mathrm{~m}, 28.06 .2019$, Başköse-4656.

\section{ONAGRACEAE}

Epilobium hirsutum L., 4, 865 m, 17.09.2018, Başköse4428.

Epilobium minutiflorum Hausskn., 6, 865 m, 6.07.2018, Başköse-4377 ve 4655 .

Oenothera biennis L., 1, 865 m, 8.07.2019, Başköse4714.

\section{OXALIDACEAE}

Oxalis corniculata L., 5,8, 865 m, 28.08.2018, Başköse4402.

\section{PAPAVERACEAE}

Chelidonium majus L., 3, 865 m, 28.06.2019, Başköse4631.

Fumaria asepala Boiss., 1,2,3, $865 \mathrm{~m}, 16.04 .2018$, Başköse-4198.

Fumaria schleicheri Soy.-Will. microcarpa (Hausskn.) Liden, 1,2,3, 865 m, 16.04.2018, Başköse-4755. 
Glaucium grandiflorum Boiss. \& A.Huet subsp. grandiflorum var. grandiflorum, 5, 865 m, 22.07.2019, Başköse-4751.

Glaucium leiocarpum Boiss., 4,5, 865 m, 16.05.2018, Başköse-4224 ve 4302.

Papaver dubium L. subp. dubium, 4, $865 \mathrm{~m}$, 16.04.2018, Başköse-4184.

Papaver rhoeas L., 4,5, 865 m, 29.04.2020, Başköse4909.

\section{PAULOWNIACEAE}

*Paulownia tomentosa Steud., 6, 865 m, 25.05.2019, Başköse-4499.

\section{PHYLLANTHACEAE}

Andrachne telephioides L., 4, 865 m, 10.06.2020, Başköse-4932.

\section{PLANTAGINACEAE}

Kickxia elatine (L.) Dumort. subsp. crinita (Mabille) Greuter, 3, 865 m, 11.09.2018, Başköse-4416.

Plantago lanceolata L., 2,3,4,7,8, 865 m, 19.06.2019, Başköse-4557.

Plantago major L. subsp. intermedia (Gilib.) Lange, 3,4,6, 865 m, 28.08.2018, Başköse-4404 ve 4685.

Plantago major L. subsp. major, 4, 865 m, 1.06.2018, Başköse-4330.

Veronica arvensis L., 3,6, 865 m, 16.05.2018, Başköse4261.

Veronica cymbalaria Bodard, 1,3, 865 m, 29.03.2019, Başköse-4478.

Veronica persica Poir., 3,4,5, 865 m, 16.05.2018, Başköse-4278 ve 4417.

Veronica triloba Opiz, 1,3,4, $865 \mathrm{~m}$, 23.02.2019, Başköse-4470.

\section{PLATANACEAE}

*Platanus acerifolia (Aiton) Willd., 1,8, $865 \mathrm{~m}$, 28.06.2019, Başköse-4684.

*Platanus orientalis L., $1 \rightarrow 8,865 \mathrm{~m}, 22.06 .2019$, Başköse-4627.

\section{POACEAE}

Aegilops biuncialis Vis., 4, 865 m, 16.05.2018, Başköse4275.

Aegilops cylindrica Host, 4, 865 m, 16.05.2018, Başköse-4276.

Aegilops triuncialis L. subsp. triuncialis, 4, $865 \mathrm{~m}$, 16.05.2018, Başköse-4256.

Alopecurus arundinaceus Poir., 5, 865 m, 20.05.2019, Başköse-4497.

Alopecurus myosuroides Huds. subsp. myosuroides, 3,5,6, 865 m, 29.04.2020, Başköse-4910.

Avena barbata Pott ex Link subsp. barbata, 4, 865 m, 16.05.2018, Başköse-4279.

Bothriochloa ischaemum (L.) Keng, 4, 865 m, 28.08.2018, Başköse-4399.

Briza humilis M.Bieb., 5, 865 m, 16.04.2018, Başköse4191.
Bromus japonicus Thunb. subsp. japonicus, 7, $865 \mathrm{~m}$, 16.05.2018, Başköse-4292.

Bromus sterilis L., 3,4,7, 865 m, 16.04.2018, Başköse4207.

Catapodium rigidum (L.) C.E.Hubb. subsp. rigidum var. rigidum, 4, 865 m, 16.05.2018, Başköse-4291.

Cynodon dactylon (L.) Pers. var. dactylon, 5,6, 865 m, 8.07.2019, Başköse-4705.

Dactylis glomerata L. subsp. hispanica, 1,3,4,5,6, 865 m, 16.05.2018, Başköse-4226.

Digitaria sanguinalis (L.) Scop., 4, 865 m, 26.07.2018, Başköse-4389,

Echinaria capitata (L.) Desf., 4, 865 m, 16.05.2018, Başköse-4272.

Echinochloa crus-galli (L.) P.Beauv., 4,6, 865 m, 28.08.2018, Başköse-4398.

Elymus hispidus (Opiz) Melderis subsp. hispidus, 4,5, 865 m, 16.05.2018, Başköse-4247.

Festuca arundinacea Schreb. subsp. arundinacea, 4,5, 865 m, 23.05.2018, Başköse-4306.

Festuca valesiaca Schleich. ex Gaudin, 4, $865 \mathrm{~m}$, 16.05.2018, Başköse-4274.

Hordeum bulbosum L., 6, 865 m, 1.06.2018, Başköse4327.

Hordeum murinum L. subsp. glaucum (Steud.) Tzvelev, 3,4,5,6, 865 m, 19.06.2019, Başköse-4556.

Melica ciliata L. subsp. ciliata, 4, $865 \mathrm{~m}, 1.06 .2018$, Başköse-4338.

Phalaris canariensis L., 1, 865 m, 7.06.2019, Başköse4517.

Phleum exaratum Griseb. subsp. exaratum, 5, $865 \mathrm{~m}$, 16.05.2018, Başköse-4250 ve 4312.

Poa bulbosa L., 3,5, 865 m, 8.07.2019, Başköse-4711.

Poa pratensis L., 3,4, 865 m, 16.05.2018, Başköse-4236.

Setaria viridis (L.) P.Beauv., 3,4,5, 865 m, 28.08.2018, Başköse-4403.

Sorghum halepense (L.) Pers. var. halepense, 6,7, 865 m, 6.07.2018, Başköse-4376.

Triticum aestivum L., 1,3, 865 m, 7.06.2019, Başköse4526.

\section{POLYGONACEAE}

*Fallopia baldschuanica (Regel) Holub, 2,4, 865 m, 19.06.2019, Başköse-4564.

Polygonum arenastrum Boreau, 5, 865 m, 17.09.2018, Başköse-4426 ve 4563.

Polygonum aviculare L., 1, $865 \mathrm{~m}$, 16.05.2018, Başköse-4230.

Polygonum cognatum Meisn., 5, 865 m, 16.05.2018, Başköse-4204.

Persicaria lapathifolia (L.) Delarbre., 3,4, $865 \mathrm{~m}$, 28.08.2018, Başköse-4395.

Rumex conglomeratus Murray, 5, 865 m, 16.04.2018, Başköse-4112.

Rumex crispus L., 3,5,6, 865 m, 16.05.2018, Başköse4277 ve 4326.

\section{PORTULACACEAE}

Portulaca oleracea L., 2, 865 m, 2.07.2018, Başköse4365. 


\section{PRIMULACEAE}

Anagallis arvensis L. var. arvensis, 7, 865 m, 13.06.2019, Başköse-4545.

Anagallis foemina Mill., 4,5, 865 m, 25.05.2019,

Başköse-4510.

*Cyclamen hederifolium Aiton, 3, 865 m, 2.10.2019.

\section{RANUNCULACEAE}

Adonis flammea Jacq., 5, 865 m, 29.04.2020, Başköse4902.

Anemone blanda Schott \& Kotschy, 3, $865 \mathrm{~m}$, 13.03.2020, Başköse-4891.

Ceratocephala testiculata (Crantz) Besser, 1, $865 \mathrm{~m}$, 11.03.2019, Başköse-4475.

Consolida orientalis (J.Gay) Schrödinger, 1,4, 865 m, 16.05.2018, Başköse-4280-4303.

*Ficaria verna Huds., 1, 865 m, 29.04.2020, Başköse4907.

*Helleborus orientalis Lam., 3, 865 m, 13.04.2020, Başköse-4900.

Nigella arvensis L. var. glauca (Boiss.) N.Terracc., 4, 865 m, 2.07.2018, Başköse-4369.

Ranunculu sarvensis L. 4, 865 m, 12.05.2020, Başköse4901.

Ranunculus bulbosus L. subsp. aleae (Willk.) Rouy \& Fouc, 8, 865 m, 16.05.2018, Başköse-4265.

Ranunculus damascenus Boiss. \& Gaill., 8, 865 m, 16.04.2018, Başköse-4212.

Ranunculus neopolitanus Ten., 3,4, 865 m, 14.11.2018, Başköse-4461.

\section{RESEDACEAE}

Reseda lutea L. var. lutea, 1,3,4,5,6, 865 m, 16.05.2018, Başköse-4254.

\section{RHAMNACEAE}

*Rhamnus rhodopaeus Velen., 6, 865 m, 25.05.2019, Başköse-4508.

\section{ROSACEAE}

*Chaenomeles speciosa (Sweet) Nakai, 4,6, $865 \mathrm{~m}$, 28.06.2019, Başköse-4680.

* Cotoneaster dammeri C. Schneider, 4, $865 \mathrm{~m}$, 22.06.2019, Başköse-4625.

*Cotoneaster francbetii Boiss., 4, 865 m, 28.06.2019, Başköse-4676.

*Cotoneaster horizontalis L., 3,5,7,8, $865 \mathrm{~m}$, 22.06.2019, Başköse-4571.

*Cotoneaster lacteus W.W.Sm., $1 \rightarrow 8,865 \mathrm{~m}$, 22.06.2019, Başköse-4576.

Cotoneaster nummularius Fisch. \& C.A.Mey., 3,4, 865 m, 20.05.2019, Başköse-4495 ve 4507.

*Crataegus monogyna Jacq. ssp. monogyna, 1,3,4,5,6,8, 865 m, 16.04.2018, Başköse-4213 ve 4215.

*Crataegus rhipidophylla Gand. var. rhipidophylla, 3,4,5, 865 m, 28.06.2019, Başköse-4630.

*Cynonia oblonga Miller, 2,4, 865 m, 28.06.2019, Başköse-4673.

Geum urbanum L., 3,4,5, 865 m, 16.05.2018, Başköse4235 ve 4566.
*Kerria japonica (L.) DC., 6, 865 m, 25.05.2019, Başköse-4501.

*Malus domestica Borkh., 3,4, 865 m, 28.06.2019, Başköse-4671.

*Malus floribunda Siebold., 3,5, 865 m, 22.06.2019, Başköse-4582.

*Photinia x fraseri Dress., 7,8, 865 m, 28.06.2019, Başköse-4686.

Potentilla anglica Laichard., 4, 865 m, 19.06.2019, Başköse-4562.

Potentilla recta L., 6, 865 m, 29.05.2019, Başköse-4506 ve 4547.

Potentilla reptans L., 4,8, 865 m, 23.05.2018, Başköse4300.

*Prunus dulcis (Mill.) D. A. Webb, 4, 865 m, 8.07.2019, Başköse-4701.

*Prunus armeniaca L., 2,3,5, 865 m, 28.06.2019, Başköse-4681.

*Prunus avium L., 4, 865 m, 28.06.2019, Başköse-4669. *Prunus cerasifera Ehrh. ssp. pisardi (CarriŠre) Dost 1,3,7,8, 865 m, 8.07.2019,Başköse-4703.

*Prunus cerasus L., 1,2, 865 m, 28.06.2019, Başköse4683.

*Prunus domestica L., 1,3,5, 865 m, 28.06.2019, Başköse-4662.

*Prunus laurocerasus L., 3,4,5,8, 865 m, 28.06.2019, Başköse-4639.

*Prunus mahaleb L. var. mahaleb, 7,8, $865 \mathrm{~m}$, 16.05.2018, Başköse-4287.

*Prunus persica (L.) Batsch., 4, 865 m, 8.07.2019, Başköse-4702.

*Prunus serrulata Lindl., 3,7,8, 865 m, 8.07.2019, Başköse-4709.

*Pyracantha coccinea M.J. Roemer, $1,3 \rightarrow 8,865 \mathrm{~m}$, 16.05.2018, Başköse-4290.

*Pyrus communis L. subsp. communis, 1, $865 \mathrm{~m}$, 1.06.2018, Başköse-4328.

Rosa canina L., 4,5, 865 m, 28.06.2019, Başköse-4677. Sanguisorba minor subsp. balearica (Bourg. ex Nyman) Muøoz Garm. \& C.Navarro., 3 $\rightarrow 6,865 \mathrm{~m}$, 13.06.2019, Başköse-4540.

*Sorbus aucuparia L., 4,5, 865 m, 24.04.2019, Başköse-4486 ve 4532.

*Spiraea $\times$ vanhouttei (Briot) Zabel, 1,2,4,5,6, $865 \mathrm{~m}$, 22.06.2019, Başköse- 4578.

\section{RUBIACEAE}

Galium humifusum M.Bieb., 5, 13.06.2019, Başköse4542.

Galium tenuissimum M.Bieb. f. trichophorum (Kar. \& Kir.) Ehrend.\& Schönb.-Tem., 4, 865 m, 25.05.2019, Başköse- 4511.

Galium tricornutum Dandy, 1,5, 865 m, 16.05.2018, Başköse- 4246.

Rubia tinctorum L., 3,5, 865 m, 23.05.2018, Başköse4317.

Sherardia arvensis L., 3,4, 865 m, 19.06.2019, Başköse4568 . 


\section{RUTACEAE}

*Ptelea trifoliata L., 5, 865 m, 16.05.2018, Başköse4294 ve 4341.

\section{SALICACEAE}

*Populus alba L. var. alba, 6,7,8, 7.06.2019, 865 m, Başköse-4519.

*Populus nigra L. subsp. nigra, $5 \rightarrow 8,865 \mathrm{~m}$, 22.06.2019, Başköse-4604.

*Salix babylonica L. var. babylonica, 3,4, $865 \mathrm{~m}$, 22.06.2019, Başköse-4584.

*Salix caprea L., 8, 865 m, 7.06.2019, Başköse-4518.

\section{SAPINDACEAE}

*Acer campestre L. subsp. campestre, 2, $865 \mathrm{~m}$, 28.06.2019, Başköse-4668.

*Acer negundo L., $1 \rightarrow 8,865$ m, 1.06.2018, Başköse4332.

*Acer palmatum Thunb., 2,3,8, 865 m, 7.06.2019, Başköse-4521.

*Acer platanoides L., 2,6,7,8, 865 m, 17.07.2018, Başköse-4386.

*Acer pseudoplatanoides L., 2,3,4,6,7, 865 m, 17.07.2018, Başköse-4387.

*Acer saccharinum L., 7, 865 m, 7.06.2019, Başköse4522 .

*Aesculus carnea Hayne, 2,6, 865 m, 28.06.2019, Başköse-4679.

*Aesculus hippocastanum L., $1,2,3,5 \rightarrow 8,865 \mathrm{~m}$, 28.06.2019, Başköse-4661.

*Koelreuteria paniculata Laxm., 3,5, 865 m, 28.06.2019, Başköse-4629.

\section{SCROPHULARİACEAE}

*Buddleja davidii Franch., 1,4, 865 m, 6.07.2018, Başköse-4379.

Scrophularia scopolii Hoppe ex Pers. var. scopoli, 1, 865 m, 23.05.2018, Başköse-4319.

\section{SIMAURIBACEAE}

*Ailanthus altissima (Mill.) Swingle, $1 \rightarrow 8,865 \mathrm{~m}$, 28.06.2019, Başköse-4646.

\section{SMILACACEAE}

*Smilax excelsa L., 3, 865 m, 28.06.2019, Başköse4636.

\section{SOLANACEAE}

Atropa belladonna L., 1, 865 m, 7.06.2019, Başköse4529.

Datura stramonium L., 5, 865 m, 23.10.2018, Başköse4445a.

Hyoscyamus niger L., 5, 865 m, 29.04.2020, Başköse4908.

*Lycium barbarum L., 4,5, 865 m, 22.06.2019, Başköse-4593.

Solanum dulcamara L., 3,4,5, 865 m, 2.07.2018, Başköse-4367.

Solanum americanum Mill., 2,5, 865 m, 17.09.2018, Başköse-4766.

\section{TAMARICACEAE}

*Tamarix smyrnensis Bunge, 1,4, 865 m, 1.06.2018, Başköse-4329.

\section{ULMACEAE}

*Ulmus glabra Hudson, 1,3, 865 m, 17.04.2018, Başköse-4485.

\section{URTICACEAE}

Parietaria judaica L., 3,5, 865 m, 6.07.2018, Başköse4380 .

Urtica dioica L. subsp. dioica, 4, 865 m, 25.05.2019, Başköse-4513.

\section{VERBENACEAE}

Verbena officinalis L. var. officinalis, 3,5, $865 \mathrm{~m}$, 29.06.2018, Başköse-4345.

\section{VIOLACEAE}

Viola odorata L., 2,3,5,6,7, 865 m, 28.06.2019, Başköse-4689.

\section{VITACEAE}

*Parthenocissus quinquefolia (L.) Planch., 1,2,5 $\rightarrow$, 865 m, 22.06.2019, Başköse-4596.

*Vitis vinifera L., 5,6, 865 m, 28.06.2019, Başköse4638 .

\section{ZYGOPHYLLACEAE}

Tribulus terrestris L., 3,5, 865 m, 28.08.2018, Başköse4408.

\section{Sonuçlar ve tartışma}

Yapılan çalışma sonucunda yerleşke sınırları içerisinde toplanan 750 bitki örneğinin değerlendirilmesi sonucunda, 79 familyadan, 282 cinse ait tür ve tür altı düzeyde toplam 445 takson tespit edilmiştir. Mevcut taksonlardan 30 tanesi Gymnospermae alt şubesine, geriye kalan 415 tanesi (monokotil gruptan 57 takson, Ödikotil gruptan 357 takson ve Ödikotil olmayan bazal gruba ait 1 takson) ise Angiospermae alt şubesine aittir.

Çalışma kapsamında gerekli floristik kıyaslamaların yapılabilmesi amacıyla, bu çalışma ile birlikte yakın çevrede gerçekleştirilmiş benzer 5 farklı çalışmanın listesi aşağıda verilmiştir. Kıyaslamalar yapılırken çalışmaların adların yerine listedeki kod numaraları kullanılmıştır. 
1. Ankara Üniversitesi 10. Y1l (Beşevler) Yerleşkesi Florası.

2. Hacıkadın Vadisinin Florası (Ankara) [25].

3. Beytepe Kampüsü (Ankara) Florası [26, 27].

4. Başkent Üniversitesi Bağlıca Yerleşkesinin (Ankara) Florası [28].

5. Anadolu Üniversitesi (Eskişehir) Kampüs Florası [1].

6. Kırıkkale Üniversitesi Kampüs Florası [4].

Çalışma kapsamında taksonların fitocoğrafik bölgelere göre dağılımları dikkate alındığında; ilk sırada 41 taksonla temsil edilen Avrupa-Sibirya fitocoğrafik bölge elementleri, ikinci sırada 33'er taksonla temsil edilen Akdeniz ve Iran-Turan fitocoğrafik bölge elementleri yer almaktadır (Tablo 2). Geriye kalan 338 takson (\% 76.0) ya fitocoğrafik olarak bölgesi bilinmemekte ya da çok bölgeli yayılışa sahiptir. Normalde İç Anadolu bölgesinde yapılan floristik çalışmaların büyük çoğunluğunda, taksonların fitocoğrafik bölgelere göre dağılımları sırasıyla Iran-Turan, Akdeniz ve Avrupa-Sibirya şeklinde ortaya çıkmaktadır. Bizim çalışmamızda bu sıralama tam tersi şeklinde gerçekleşmiştir. Bunun temel sebebi Avrupa-Sibirya elementlerinin büyük çoğunluğunun plantasyon sonucu kampüs alanı içerisinde bulunmasından kaynaklanmaktadır.

Ayrıca elde edilen bulgular yakın çevrede yapılan diğer çalışmalarla kıyaslandığında 2, 3, 4 ve 6 numaralı çalışmalarda ilk sırada Iran-Turan elementleri, 5 numaralı çalışmada bizim çalışmamızda olduğu ilk sırada AvrupaSibirya elementleri ilk sıradadır. Ayrıca 2 ve 3 numaralı çalışmalarda ikinci sırada Avrupa-Sibirya ve üçüncü sırada Akdeniz fitocoğrafik bölge elementleri, 4 ve 6 numaralı çalışmalarda ikinci sırada Akdeniz elementleri ve üçüncü sırada ise Avrupa-Sibirya elementleri, 5 numaralı çalışmada ikinci sırada Iran-Turan ve üçüncü sırada ise Akdeniz fitocoğrafik bölge elementleri yer alırken, bizim çalışmamızda 33'er taksonla Akdeniz ve Iran-Turan elementleri ikinci sırada bulunmaktadır.

Tablo 2. Çalışma alanına ait fitocoğrafik bölge elementlerinin yakın çevredeki diğer çalışmalar (yakın kampüsler ve yakın alanlar) ile kıyaslanmasi

\begin{tabular}{|l|c|c|c|c|c|c|c|}
\hline Yapılan çalışmalar & $\mathbf{1}$ & $\mathbf{2}$ & $\mathbf{3}$ & $\mathbf{4}$ & $\mathbf{5}$ & $\mathbf{6}$ \\
\hline $\begin{array}{l}\text { Takson sayısı } \\
\text { Fitocoğrafik Bölge }\end{array}$ & & $\mathbf{4 4 5}$ & $\mathbf{4 8 0}$ & $\mathbf{5 1 0}$ & $\mathbf{3 8 2}$ & $\mathbf{3 6 3}$ & $\mathbf{3 7 1}$ \\
\hline Akdeniz & $\%$ & 7.4 & 8.9 & 3.0 & 5.2 & 3.3 & 7.3 \\
\hline Iran-Turan & $\%$ & 7.4 & 18.5 & 27.0 & 31.2 & 7.7 & 26.9 \\
\hline Avrupa-Sibirya & $\%$ & 9.2 & 9.3 & 6.0 & 3.9 & 8.8 & 2.5 \\
\hline Çok Bölgeli veya Bilinmeyenler & $\%$ & 76.0 & 63.1 & 63.5 & 59.7 & 80.2 & 63.2 \\
\hline
\end{tabular}

Yapılan bu çalışmada en çok taksona sahip familyalar dikkate alındığında, ilk sırada Asteraceae familyası, ikinci sırada ise Fabaceae familyası yer almaktadır. Bu durum hem diğer floristik çalışmalar hem de "Türkiye Florası" ile kıyaslandığında benzer olduğu görülmektedir. Bizim çalışmamızda Rosaceae familyası içerdiği takson sayısı bakımından \% 7.2 oranında bir değer ile üçüncü sırada yer almaktadır (Tablo 3). Bunun nedeni, familyaya ait çok sayıda ağaç ve çalı türlerinin kampüs alanında plantasyona bağlı olarak temsil edilmesindendir. Buna karşılık 2, 3, 4, 5 ve 6 numaralı çalışmalarda Rosaceae familyası ilk 5 familya içerisinde temsil edilmemektedir.

Tablo 3. Çalışma alanına yakın kampüsler ve yakın bölgelerde yapılan çalışmalarda en çok taksona sahip familyanın kiyaslanmasi.

\begin{tabular}{|l|c|c|c|c|c|c|c|}
\hline \multicolumn{2}{|l|}{ Yapılan çalışmalar } & $\mathbf{1}$ & $\mathbf{2}$ & $\mathbf{3}$ & $\mathbf{4}$ & $\mathbf{5}$ & $\mathbf{6}$ \\
\hline $\begin{array}{l}\text { Takson sayısı } \\
\text { Familyalar }\end{array}$ & $\mathbf{4 4 5}$ & $\mathbf{4 8 0}$ & $\mathbf{5 1 0}$ & $\mathbf{3 8 2}$ & $\mathbf{3 6 3}$ & $\mathbf{3 7 1}$ \\
\hline Asteraceae & $\%$ & 9.6 & 11.5 & 14.7 & 13.6 & 9.9 & 12.9 \\
\hline Fabaceae & $\%$ & 8.3 & 10.2 & 12.9 & 11.5 & 7.9 & 12.7 \\
\hline Rosaceae & $\%$ & 7.2 & ---- & ---- & ---- & ---- & ---- \\
\hline Poaceae & $\%$ & 6.5 & 6.9 & 6.9 & 7.3 & 4.6 & 7.8 \\
\hline Brassicaceae & $\%$ & 4.5 & 6.7 & 8.0 & 8.4 & 4.9 & 9.7 \\
\hline
\end{tabular}

Ayrıca en fazla takson içeren cinsler dikkate alındığında, çalışmamızda Medicago ve Prunus cinsleri 10'ar taksonla ilk sırayı paylaşmaktadır. Bunları 6'şar takson ile temsil edilen Acer, Atriplex ve Juniperus cinsleri ile 5'er taksonla temsil edilen Crataegus, Berberis, Pinus ve Trifolium cinsleri takip etmektedir. Bu durum, ne yakın çevrede yapılan diğer çalışmalar ne de "Türkiye Florası" verileri ile örtüşmemektedir. Çalışma alanımızın şehir merkezi içerisinde çok dar bir alan olarak sınırlanması, doğal alan özelliği göstermemesi ve alan içerisinde habitat çeşitliliğine sahip olmaması bu sonucu ortaya çıkarmıştır.

Çalışma alanında belirlenen taksonların 8 tanesi endemik olup endemizm oranı \% 1.8'dır. Tablo 4 incelendiğinde en düşük endemizm oranı bizim çalışmamızda ortaya çıkmıştır. Bunun temel sebebi çalışma alanın hem çok küçük olması 
hem de endemizm oranının yüksek olmasını sağlayan habitat çeşitliliğinin olmamasından ileri gelmektedir. Bu sekiz endemik taksondan altısı çeşitli dönemlerde Fen ve Eczacılık fakültelerinden botanikçilerin gurbette koruma çalışmaları amacıyla yerleşkeye taşıdıkları bitkilerdir (Astragalus beypazaricus, Allium karamanoglui, Scilla luciliae, Sternbergia candida, Salvia aytacii, Crocus ancyrensis). Dolayısıyla kampüs alanında doğal olarak sadece iki endemik bitki yer almaktadır (Onopordum anatolicum ve Alyssum huetii).

Endemik taksonların IUCN tehlike kategorilerine göre dağılımları dikkate alındığında; 1 taksonun (Astragalus beypazaricus) CR, 2 taksonun (Allium karamanoglui ve Scilla luciliae) EN, 2 taksonun (Sternbergia candida, Salvia aytacii) VU ve geriye kalan 3 taksonun (Onopordum anatolicum, Crocus ancyrensis ve Alyssum huetii) ise LC kategorisinde yer aldığ 1 belirlenmiştir.

Tablo 4. Çalışma alanındaki taksonların endemizm oranı ve çevredeki diğer çalışmalar (yakın kampüsler ve yakın alanlar) ile kıyaslanması

\begin{tabular}{|l|c|c|c|c|c|c|c|}
\hline Yapılan çalışmalar & $\mathbf{1}$ & $\mathbf{2}$ & $\mathbf{3}$ & $\mathbf{4}$ & $\mathbf{5}$ & $\mathbf{6}$ \\
\hline \multicolumn{2}{|l|}{ Takson sayısı } & $\mathbf{4 4 5}$ & $\mathbf{4 8 0}$ & $\mathbf{5 1 0}$ & $\mathbf{3 8 2}$ & $\mathbf{3 6 3}$ & $\mathbf{3 7 1}$ \\
\hline \multicolumn{2}{l|}{ Çalış1lan Alanın Büyüklü̆̆̈̈̈ } & $0.19 \mathrm{~km}^{2}$ & $2.7 \mathrm{~km}^{2}$ & $12.0 \mathrm{~km}^{2}$ & $3.6 \mathrm{~km}^{2}$ & $0.85 \mathrm{~km}^{2}$ & $2.3 \mathrm{~km}^{2}$ \\
\hline Endemizm oranı & $\%$ & 1.8 & 9.3 & 12.7 & 16.5 & 3.0 & 12.1 \\
\hline
\end{tabular}

Yapılan arazi çalışmaları sırasında Acer platanoides L., Aesculus hippocastanum L., Ailanthus altissima (Mill.) Swingle, Celtis australis L., Mahonia aquifolium (Pursh) Nutt. ve Quercus robur L. gibi kampüs alanında plantasyon sonucu bulunan bazı türlerin zaman içerisinde gerek vejetatif gerekse de generatif şekilde çoğalarak yerleşke içerisinde doğallaştıkları gözlenmiştir.

Aynı zamanda Çizelge 4.3'e göre özellikle çalışma alanlarının büyüklüklerine göre kıyaslama yapıldığında, Ankara Üniversitesi 10. Y1l yerleşkesinin en küçük yüz ölçüme sahip olmasına rağmen birim alana düşen takson sayıs1 bakımından $\left(0.002 / \mathrm{m}^{2}\right)$ ilk sırada olduğu görülmektedir. Bu durum kampüs alanının sahip olduğu bitki zenginliğini ortaya koyan diğer göstergedir. Birim alana düşen takson sayısı bakımından ikinci sırada 5 numaralı $\left(0.00040 / \mathrm{m}^{2}\right)$, üçüncü sırada 2 numaralı $\left(0.00020 / \mathrm{m}^{2}\right)$, dördüncü sırada 6 numaralı $\left(0.00016 / \mathrm{m}^{2}\right)$, beşinci sırada 4 numaralı $\left(0.00011 / \mathrm{m}^{2}\right)$ ve son sirada ise 3 numaralı $\left(0.00004 / \mathrm{m}^{2}\right)$ çalışma yer almaktadır.

Ankara Üniversitesi 10. Yıl yerleşkesi yakın geçmişte (geçmişteki adıyla Fen Fakültesi Bahçesi) botanik bahçesi özelliğine sahip bir alanken yıllar içinde artan ihtiyaçlarla orantılı olarak artan yapılaşma, insan yoğunluğu ve sera ve bahçıvanlık hizmetlerine kaynak ayrılamaması nedeni ile bu özelliğini giderek kaybetmiştir. Tüm bunlara rağmen kısıtlı bir alanda bu denli çok sayıda tohumlu bitki taksonunun bulunması alanın geçmişteki bitkisel zenginliğinin bir yansimasidir.

\section{Teşekkür}

Bu çalışmayı maddi olarak 18B0430001 numaralı proje ile destekleyen Ankara Üniversitesi Bilimsel Araştırma Projeleri (BAP) Koordinatörlüğüne teşekkürlerimizi sunarı.

\section{Kaynaklar}

[1] Türe, C. \& Böcük, H. (2001). The Flora of The Anadolu University Campus (Eskisehir-Turkey). Anadolu Üniversitesi Bilim Ve Teknoloji Dergisi, 2(1): 83-95.

[2] Parmaksiz, A., Atamov, V. \& Aslan, M. (2006). The Flora of Osmanbey Campus of the Harran University. Journal of Biological Sciences, 6(5): 793-804.

[3] Ünal, O. \& Gökçeoğlu, M. (2003). Akdeniz Üniversitesi Kampus Florası (Antalya-Türkiye). Akdeniz Üniversitesi Ziraat Fakültesi Dergisi, 16(2): 143-154.

[4] Nugay, Ö.Z., Duran, A. \& Doğan, B. 2007. Kırıkkale Üniversitesi Kampüs Florası. S.Ü. Fen-Edeb. Fak. Fen Dergisi, 30: 79-92.

[5] Mutlu, B. \& Karakuş, Ş. (2015). Floristic List of İnönü University (Malatya) Main Campus Area. Hacettepe Journal of Biol. \& Chem., 43(2): 73-89.

[6] Salık, V. \& Güler, N. (2018). Trakya Üniversitesi Balkan Yerleşkesinin Florası, Trakya University Journal of Natural Science, 19(1): 33-50.

[7] Bal, A.N. \& Abay, G. (2019). Landscape Plants of Recep Tayyip Erdoğan University, Zihni Derin Campus (RizeTurkey). Journal Anatolian Env. and Anim. Sciences, 4(1): 11-15.

[8] Akata, I., Doğan, H.H., Körüklü, T. \& İşlek, C. (2009). Ankara Üniversitesi Tandoğan Kampüsü Makrofunguslar1. Kafkas Üniversitesi Fen Bilimleri Enstitüsü Dergisi, 2(1): 15-19.

[9] Akata \& Heluta, V.P. (2015). First record of Erysiphe syringae-japonicae in Turkey. Mycotaxon, 130: $259-264$.

[10] Akata, I., Altuntaş, D. \& Kabaktepe, Ş. (2019). Fungi Determined in Ankara University Tandoğan Campus Area (Ankara-Turkey). Trakya Univ. Jour. of Nat. Sci. 20(1): 47-55.

[11] Akman, Y. (2011). İklim ve Biyoiklim, Ankara, Palme Yayınları No: 597, 345 p. 
[12] Davis, P.H. (eds), 1965-1985. Flora of Turkey and the East Aegean Islands. v: 1-9, Edinburgh University Press, Edinburgh.

[13] Davis, P. H, Mill, R.R. and Tan, K., 1988. Flora of Turkeyand the East Aegean Islands. v: 10 Edinburgh University Press, Edinburgh, 1-590.

[14] Güner, A., Aslan, S., Ekim, T., Vural, M. ve Babaç, M.T.(Edlr.), 2012. Türkiye Bitkiler Listesi (Damarlı Bitkiler). Nezahat Gökyiğit Botanik Bahçesi ve Flora Araştırmaları Derneği Yayını, İstanbul, 1-1290.

[15] Akkemik, Ü. (2014a). Türkiye’nin Doğal-Egzotik Ağaç ve Çalıları-I. Ankara, Orman Genel Müdürlüğü Yayınları, $736 \mathrm{p}$.

[16] Akkemik, Ü. (2014b). Türkiye’nin Doğal-Egzotik Ağaç ve Çalılart-II. Ankara, Orman Genel Müdürlüğü Yayınlar1, $680 \mathrm{p}$.

[17] Akaydın, G. (2015). Ankara Şehrinin Doğal Bitkileri. Ankara, Hacettepe Üniversitesi Basımevi, 497 p.

[18] Demirtaş, A. (2016). Ankara'nın A ̆gaç, Ağaççık ve Çalıları. Ankara, Kırsal Çevre ve Ormancılık Sorunları Araştırma Derneği Yayını No:17.

[19] Brummitt, R.K. 1999. Powell, C.E. Authors of Plant Names, The Royal Botanic Gardens, Kew, USA. [1] Akman, Y. (2011). İklim ve Biyoiklim, Ankara, Palme Yayınları No: 597.

[20] Anonim, (2019a). The Plant List. https://www.theplantlist.org.

[21] Anonim, (2019b). International Plant Names Index (IPNI). https://www.ipni.org.

[22] Ekim, T., Koyuncu, M., Vural, M., Duman, H., Aytaç, Z. \& Adıgüzel, N. (2000). Türkiye Bitkileri Kırmızı Kitabı (Ĕgrelti ve Tohumlu Bitkiler). Ankara. Türkiye Tabiatını Koruma Derneği ve Yüzüncü Yıl Üniversitesi.

[23] IUCN (2019). Guidelines for Using the IUCN Red List Categories and Criteria. Version 14. Prepared by the $\begin{array}{lllll}\text { Standards and } & \text { Petitions } & \text { Dommittee. }\end{array}$ http://www.iucnredlist.org/documents/RedListGuidelines.pdf.

[24] Anonim, (2019c). Ankara İli İklim Verileri, Devlet Meteoroloji İşleri Genel Müdürlüğü, Ankara.

[25] Yeşilyurt, E.B., Kurt, L. \& Akaydın. G. (2008). A study on Flora of Hackkadın Valley. Biological Diversity and Conservation, 1(2): 25-52.

[26] Erik, S. (1994). Beytepe Kampüsü (Ankara) Florası. Hacettepe Fen ve Mühendislik Fakültesi Dergisi, Seri A, 15: 49-109.

[27] Mutlu, B., Erik, S. \& Tarikahya, B. (2008). New Contributions to The Flora of Beytepe Campus (Ankara) and Floristic Comparison With Neighboring Floras and Other Campus Floras. Hacettepe Journal of Biol. \& Chem., 36(3): 181-195.

[28] Töre, D. \& Erik, S. (2012). The Flora of Bağlıca Campus of Başkent University (Ankara). Hacettepe Journal of Biol. \& Chem., 40(3): 267-291. 